\title{
A HUMANISING ECONOMIC APPROACH ON COMPETITION POLICY OR HOW THE BEHAVIORAL ECONOMICS BLENDS WITH “TRADITIONAL ECONOMICS”
}

\author{
Liviana Andreea Nimineț \\ “Vasile Alecsandri” University of Bacau \\ liviananiminet@yahoo.com
}

\begin{abstract}
Behavioral are crucial for understanding both the consumer's attitude and firms' attitude as well as for understanding the market outcomes. The past ten years brought a lot of attention from researchers and policy-makers on the behavioral economics issue. Classical, traditional economic models rely on the assumptions of rationality and ordered preferences. Behavioral economics explores interactions between demand and supply including information framing, the use of heuristics in decision-making and time-inconsistent preferences. The research on behavioral economics has led to an extensive debate about the relative merits of both traditional and behavioral economics. First of all we propose to highlight the advantages and disadvantages of behavioral economics versus traditional economics on a very sensitive issue: the competition policy. Then we address market issues that can be solved by means of behavioral economics afterwards turning out attention to the remedies of behavioral economics and ,last but not least, the United Kingdom successful model on the matter of competition policy.
\end{abstract}

\section{Keywords}

Behavioral economics; competition policy; consumers

JEL Classification

E03; K20; L1

\section{Introduction}

Behavioral economics uses psychological perspectives in order to explain the importance of the behavioral and cognitive processes both on consumer behavior as well as in market outcomes. In the last ten years it received a lot of attention both from researcher $\mathrm{s}$ as well as from policy-makers. Latu sensu, traditional economic models rely on the assumptions of rationality and ordered preferences. Behavioral economics explores interactions between demand and supply given that "certain human cognitive and behavioral characteristics result in constrained (bounded) rationality and potential "biases in decision-making and outcomes". These characteristics include information framing, the use of heuristics in decision-making, and time-inconsistent preferences.

The research on behavioral economics has led to an extensive debate about the relative merits of both traditional and behavioral economics. A first question is whether behavioral economics is more accurate than traditional economics to predict certain market outcomes. It is not the case that behavioral economics has overthrown the existing paradigms in economics. This led to a continuous debate on the (relative) merits of traditional economics and determined vivid policy debates all over the world, in all economics related fields, including the competition policy one. 


\section{Behavioral economics vs. "traditional” economics}

There are several ways to look at the question regarding behavioral economics versus classical, traditional economics.

First of all are the "traditional" researchers that consider that the traditional economic model also explains the behavioral phenomena, so it brings nothing new. They argue that there already are traditional economic models that explain how: a) a market may fail to function where the buyers have less information about the product than the sellers do (asymmetric information); b) a buyer's demand for a good may depend not only on price but also on the demand of other buyers (network effects); and c) competition is less effective in markets where consumers face high search or switching costs. Likewise, a consumer's irrational high willingness to pay for a branded good can be captured using traditional demand curves.

Second are the researchers that consider that behavioral economics is mainly relevant in respect to the individual consumers rather than to the companies.

A part of the researchers argue that the consumer biases determine adverse outcomes and these could be better dealt with the "consumer protection policy" and not with competition policy.

\section{Behavioral economics and competition policy}

Given the above, a question remains: how much does behavioral competition affect competition policy given that in most of the cases we deal with business to business disputes. What is the importance of consumer biases in these cases? Can the "traditional" competition tools cope with that or another perspective is needed?

Let us think of costs for instance. "Traditional" economics explained all of it. Or hadn’t it?!? Well, behavioral economics surely can put what drives search costs on a different light and can explain, for instance, how product differentiation affects the behavior of a consumer. Furthermore can explain how firms might be able to exploit consumer biases. This means added value and this is all research is about: bringing added value.

Make no mistake, in competition cases one cannot simply dived them into: traditional and behavioral ones. They all exist, both of them. The difference is determined solely by the way the investigations are conducted meaning that sometimes consumer biases and bounded rationality can be a major factor in the investigation and other times could be just one aspect among others to take into consideration.

Let us see what can affect the consumer behavior? Surely product differentiation can do that in all the stages that form the demand-supply circle: access, asses and act. Given that, firms can exploit this by pricing framework. Depending on the pricing policy of the firm it may be beneficial or harmful for the consumers. Consumers profile is also crucial: a sophisticated group of consumers are harder to please than the naïve ones. All these influence market power, market shares and even can change a little bit the definition of "classical" market.

\section{Market issues and behavioral economics}

Next we propose to see how behavioral economics changes the perspective of some "traditional" market definitions tools, such as the SSNIP test.

The SSNIP test is mainly about how consumers respond to price variations rather than why do they respond to it. However, behavioral economics searches the reasons behind the consumers reaction so that to frame market definition analysis. Given the known fact that the choice of the price base to which a price increase is applied as part of the SSNIP test is crucial in obtaining a meaningful market definition the 
Behavioral economics brings a new element: Is this question relevant where more than one price is involved (e.g.: bundled products, add-ons and drip pricing). In addition may it be relevant to consider price discrimination markets based on customer groupings into sophisticated and naive customers?

The SSNIP test applied to markets with drip pricing or secondary products can find "pockets of market power-narrow markets", with market power/dominance for the provider. This means that the abuse of dominance rules could be a potentially relevant instrument to intervene in such markets in such a manner that it does not become over-intervention.

Abuse cases involving the direct exploitation of customers are extremely rare, and usually it all comes down to excessive pricing cases (opposed to other exploitative practices, for example reducing service quality). Behavioral economics proves that companies may have a greater ability to exploit their customers (or, more specifically, exploit consumer biases) than traditional models let us believe. But what does it mean for competition authorities? Should they look more closely at cases concerning exploitative abuse? Or this is an issue of consumer protection and financial regulation policies?

Regarding bundling and tying, behavioral economics argues that consumer biases may reduce competition within a particular market or between markets. Can this situation be seen as following the rules on abuse of dominance? First, a dominant position must be established and this depends on market definition and assessment of market power. Secondly there are extremely rare this type of cases concerning the abuse of dominance regulation.

All the restrictive agreement and mergers can be easily addressed using traditional approaches. Still, the behavioral economics literature brings a new perspective both on consumer and on firm biases that can be used to add additional value to the traditional approaches.

\section{Added value of behavioral economics}

First of all it is important to say that Behavioral economics puts a new perspective on the matter of how surveys for both market definition and merger analysis should be conducted so that to obtain reliable information. Psychology and behavioral economics literature have already brought their input in guiding and developing best practice in the use of surveys.

Secondly, there is great potential to use experiments in competition investigations. Experiments are an important tool for behavioral economics literature and can be added to results obtained from econometric and survey analysis. This is still an unexplored area.

Behavioral economics can be used in cases dealing directly with market outcomes and competition concerns resulting from consumer biases. However important behavioral insight can be used in cases dealing with competition problems that aren't mainly related to consumer biases.

We all know that policy-makers need to better understand demand side of markets that is how consumers really behave. The key steps for that are: collecting empirical evidence and testing the remedies.

Below is a figure representing the interactions between demand and supply highlighting the weak points, or where the cycle may break down. 


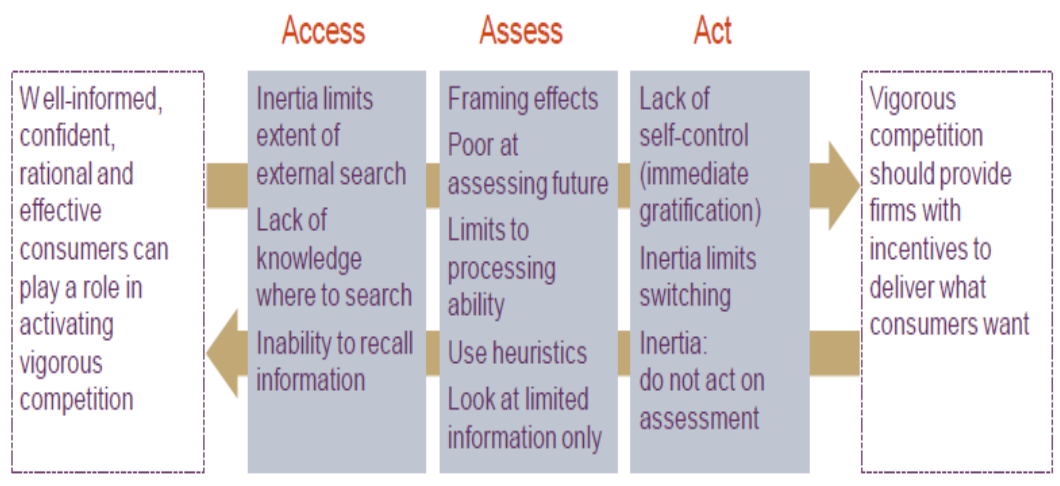

Figure 1. Demand -supply interactions

Source: Office Fair Trading 2010

\section{Behavioral economics remedies}

Behavioral economics seeks to correct these or to find ways of working with consumers` biases so that to determine a better course of action (which is more productive than trying to solve the biases). These remedies (liberal paternalist) do not deprive consumers of choice, and result in a better deal for a certain group of customers without making matters worse for other consumers.

This type of policies should include:

- simplifying information disclosure to the key points so that to overcome framing, inertia and information overload;

- determining consumers to make a choice (forced choice) rather than let them remain inert or simply opt for the default;

- using "default opt-ins or opt-outs"-whenever there is a superior outcome for consumers, the policy should propose to set that outcome as the default, without restricting consumers ability to choose an alternative.

The main advantage of these interventions comes out of the cost: a much lower cost compared with heavy interventions (education programmer is one good example). Another important advantage is that they maintain the consumers' freedom of choose altering solely the access information frame. Even if these interventions do not get through, no harm is done. These interventions aim to preserve consumers' sovereignty.

\section{Case study- market investigation in UK}

An extremely useful instrument that combines features of competition policy and consumer protection and which may be better suited for these cases rather than the abuse of dominance regulation, for instance-is the market investigation instrument in the UK.

These investigations are used in markets where competition seems to be ineffective, but still without obvious abuse of dominance or restrictive agreement.” Remedies can be imposed on a forward-looking basis to address undesired competition outcomes, including those determined by consumer biases. Other policies may wish to consider adopting such a regime, or seek other policy options so that to combine features of competition policy and consumer protection.” Intervention can be by means of competition policy or consumer protection policy 
The conceptual approaches, importance and techniques to asses market outcomes gathering empirical evidence on consumer preferences and behavior apply to consumer protection and financial regulation policies as much as they do to competition policy. For any policy instrument, we must keep in mind that not all adverse market outcomes of bounded rationality and consumer biases can be remedied by governments, partly because governments are subject to biases too.

Behavioral economics can surely enable better, smarter intervention and most of the times this does not mean more intervention, quite contrary. An analogy is needed: the same way a consumer can be affected by biases in his product purchasing process, state institution can be also affected in their decision making process.

\section{Conclusions}

Most of the behavioral economics literature deals with consumer biases as a natural extension of the analysis of humans' cognitive and behavioral characteristics

Nevertheless, companies (or the people who work for them), be they suppliers or buyers in a market, may also be characterized by bounded rationality and biases, and this can also be relevant for competition policy. There is also another, to some extend less developed, strand of the literature that deals with firms' biases. In addition, there is a strand of literature dealing with behavioral economics impact on competition policy mostly relevant for capital and securities markets. Last but not least governments (or the people who work for them) are also characterized by bounded rationality and biases. This is a very important aspect to bear in mind when discussing remedy design and policy implications of behavioral economics in general. A valuable lesson from other economic policy areas can also be applied here: market failures, even if fully identified and understood, cannot always be effectively remedied given that there can be government failures also. By the same token, not all adverse market outcomes resulting from bounded rationality and consumer biases can be remedied by governments, in part because governments are also subject to biases.

\section{References}

Armstrong, M., Huck, S. (2010), Behavioral Economics as Applied to Firms: A Primer, Competition Policy International, pp.3-45.

Armstrong, M., Vickers, J. (2012), Consumer Protection and Contingent Charges, Journal of Economic Literature, pp.477-493.

Gilbert, D. (2006), Stumbling on Happiness, Knopf.

London Economics (2010), The impact of price frames on consumers decision making, OFT Report, University College London.

Nimineț, L. (2007), The development of EU competition law in transition period. Study case, Studies and Scientific Researches. Economics Edition, no. 12, pp. 71-75.

Nimineţ, L. (2008), The Small but Significant and Nontransitory Increase in Price (SSNIP), Studies and Scientific Researches. Economics Edition, No13, ISSN 1224-985, 2008, pp.66-69.

Nimineţ, L. (2009), Competition Policy in EU and Romania during the economic crisis, Romanian Economic and Business Review, 2009, no. 4(4), pp.8994.

Nimineţ, L. (2009), European Competition Policy in time of crisis. To be or not to be, Studies and Scientific Researches. Economics Edition, No. 14, 2009, pp.67-71. 
Nimineţ, L. (2010), Adapting to the Times: The case of the EU Competition Policy regarding the Motor Vehicle Sector, Revista economica, No. 3(50), pp.372377.

Nimineț, L. (2012) Turmoil on the automotive market: insight perspective, BRAND, Vol.3, No.3, 2012, pp. 80-84.

Niminet, L. (2014), Changing the economic parameters of competition environment, Berlin, Lambert Academic Publishing (LAP).

Niminet, L. (2014) Regulation and enforcement of competition policy, Studies and Scientific Researches. Economics Edition No 21/2014, pp 19-24.

Thaler, R.H. (1994), The Winner's Curse: Paradoxes and Anomalies of Economic Life, Princeton University Press.

Weaver, F.S. (2010), Economic Literacy: Basic Economics with an attitude, Rowman\&Littlefield Publishers. 